\title{
Review of the literature discussing the problem of uneven thermal stresses in the furnace chamber
}

\author{
Marek Majdak ${ }^{1, *}$ \\ ${ }^{1}$ Institute of Thermal Power Engineering, Cracow University of Technology, al. Jana Pawła II 37, 31-864 Kraków, Poland
}

\begin{abstract}
Uneven thermal stresses occurring in the walls of the furnace chamber in high power boilers are the reason for the occurrence of significant thermal stresses. The occurrence of excessive stress leads to serious damage to the waterwall tubes, which result in the necessity of more frequent repairs of the boiler. Therefore, finding a way to reduce stress values is one of the key challenges in improving productivity and increase the service life of boilers.

In this paper will be presented the review of the literature concerning the problem of uneven temperature distribution on the surface of the combustion chamber walls. There will also be presented studies that discuss the methods of modifying the furnace chamber to reduce the values of the stresses occurring in it.
\end{abstract}

\section{Literature review}

Flow-through boilers for supercritical parameters allow obtaining parameters exceeding the values characteristic for the critical point of water, which results in a factor for which there is no boundary between the liquid and gas phases. In boilers of this type, it is particularly important to care for the safety of hydraulic components, which is determined by controlling the temperature of the flow elements, the absence of pulsation of the medium flow, installation of protection to prevent the occurrence of stagnation or backflow in the boiler [1].

To precisely determine the working conditions of the walls of the furnace chamber, numerous analyzes were carried out based on the division of waterwall tubes and the factor flowing through them into finite elements. Determining the working conditions of furnace chamber walls using direct measurements is particularly difficult due to the high temperatures at which the measuring devices must be operated. To stabilize the measurement conditions and protect the measuring devices against damage numerous elements attached to the tested walls of the firing chambers are used. The design and principle of operation of one of these elements is described in [2].

The main problem related to the changing conditions of waterwall tube work is the identification of waterwall tube parameters on the thickness of their cross-section in the event of a transient thermal state of their operation. One of the methods of identifying these parameters in online mode is the method proposed in [3], allowing to determine the temperature distribution of the material from which the furnace chamber walls are made, and the temperature distribution of the medium flowing through the waterwall tubes based on heat transfer equations solved using methods of elementary balances.
Another method of solving the inverse problem in cylindrical elements, i.e. determining the temperature distribution on the cross-section of a thick-walled element based on the temperature measured on its external surface, taking into account the variable material parameters in which the analyzed elements are made and taking into account variable factor parameters, has been proposed in [4]. The temperature distribution in the wall of the element was determined using the simple method, taking into account the dependence of the thermophysical properties of the material and the temperature of the medium inside the tubes.

Another issue that should be taken into account in order to properly model the temperature distribution and stresses occurring in the waterwall tubes mounted on the furnace chamber walls is the problem of determining the dynamics of changes in material parameters due to a rapid change in their working conditions - rapid temperature change at the inlet to the waterwall tube or step change heat flux falling on the wall of the furnace from the outside. One of the solutions developed for this problem, based on the use of a differential scheme in explicit and implicit form, has been presented in [5].

The boiler evaporator dynamics model, based on the solution of balance equations describing the principles of energy, mass and momentum conservation, has been presented in [6]. This model is a model with distributed parameters, described by differential equations with separated variables. By using this model, it is possible to determine the exact temperature and stress distribution in the boiler of the power boiler, taking into account the thermophysical properties of the material from which the evaporator is made and time parameters of the medium that passes through it.

The mathematical model allowing for the analysis of heat exchange processes occurring in boiler furnace

\footnotetext{
*Corresponding author: marek.majdak@mech.pk.edu.pl
} 
chamber waterwalls for supercritical parameters was also presented in [7]. In the article is presented a methodology for solving equations of energy, mass and momentum balance, based on the model proposed in [5] and computational verification of obtained results together with comparing them with other strict solutions for transients available in the literature.

In the literature, there are also available analyzes of the thermal load distribution at the height of the furnace chamber. In [8-10], the results of calculations of the thermal load distribution determined by measurements of the face temperature of the waterwall tube are presented using a measurement insert that allows obtaining more accurate measurement results, assuming a constant temperature of the medium flowing inside the analyzed waterwall tube.

The paper [11] presents the results of numerical computations performed for the supercritical boiler's furnace chamber waterwalls with a steam output of $2400 \times 10^{3} \mathrm{~kg} / \mathrm{h}$. The model is based on the solution of equations describing the conservation of mass, momentum and energy. The aim of the calculations is to determine the distribution of mass flow, enthalpy and the fluid pressure in tubes, using the Runge-Kutta method to solve the system of ordinary differential equations.

Another method of modifying the heat exchange process in high-power power boilers is the use of internally rifled tubes. The articles [12-14] present the results of calculations and numerical simulations allowing for the comparison of the heat exchange process in smooth tubes and internally rifled tubes, which have an increased internal surface area.

A comprehensive analysis of the heat exchange phenomenon occurring in the furnace of a fluidized bed boiler with a circulating bed, taking into account the phenomena occurring between adjacent particles moving inside the bed, and between the bed and the boiler furnace wall is presented in [15]. The study also discusses the heat transfer between the waterwall tubes and the fluid flowing through them, as well as the influence of tube grooving on the heat exchange intensity.

The problem of the analysis of phenomena related to heat exchange in furnace chambers of fluidized bed boilers has also been described in [16]. The authors of the study discussed the problem with consideration of the division into two processes - the transfer of heat between the gas and the particles of the bed, and the transfer of heat between the fluidized bed and the surface of the tubes immersed in the bed.

An extensive analysis of the calculation of thermohydraulic operating conditions of a fluidized bed boiler with a circulating bed operating on supercritical parameters is presented in [17-19]. Authors presented the assumptions of the mathematical model allowing analysis of the boiler's operation taking into account the variable mass flow of the circulating factor in it, and presented changes in the temperature distribution of the circulating medium and metal from which the furnace chamber is made in selected circulation contours depending on the boiler load and stream size mass of the medium flowing through the boiler.
The design and working conditions of the fluidized bed boiler, in which the Benson type evaporator was used, i.e., the evaporator built of vertical waterwall tubes, allowing to determine the mass flow of the medium flowing through the individual waterwall tubes, depending on the thermal load affecting them, are described in [20]. The use of the presented method allows to reduce hydraulic losses and reduce the stresses occurring in the boiler furnace chambers, mainly during boiler operation under a reduced mass stream of the heat-receiving medium.

The author of the publication [21] presents in it some of the most common causes of failure of pressure elements of boilers, with particular emphasis on the surfaces of firing chamber waterwalls. One of the most important causes of failure, which is based already in the wrong design of the furnace chamber, is the problem of overheating of waterwall tubes to a temperature exceeding the limit value. As a result of exceeding the permissible temperature, the material's creep strength decreases dramatically - this phenomenon can be significantly reduced by using the proposed layout of waterwall tubes with different pitch distribution on the width of the furnace chamber.

The studies [22-24] present new models of the division of the boiler waterwall tube with the adjacent fin on the control volume. The temperature distributions for the medium and selected cross-sectional points of waterwall tubes at various heights were presented, based on data regarding working conditions for one of the Polish power plants operating on supercritical parameters.

The comparison of the influence of changes in the parameters of the fluidized bed boiler with a circulating bed on the phenomenon of heat exchange occurring in the combustion chamber is presented in [25]. The authors of the study focused on the comparison of known computational models and the determination of the impact of fluidized bed density on heat exchange in the boiler's furnace chamber.

The paper [26] discusses the process of remodeling the EKM-1,3 grate boiler for an OF-1,3 fluidized boiler. The authors of the article focused on the discussion of installed and modernized boiler components, as well as on the analysis of the results of tests carried out, in a wide range of operating parameters, in a fixed and unchanged boiler operating condition. The test results can be used during the design process of the fluidized bed boiler as well as during its operation.

The description of the structure and principles of operation of the world's first fluidized bed boiler for supercritical parameters with a vertical arrangement of the evaporator tubes was presented in [27]. The authors of the article focused on discussing the process of setting up the installation, determining the parameters of the fuel for which combustion was designed, as well as discussing individual elements of the system that makes up the water-steam cycle. The parameters of the boiler's evaporator's operation with the vertical arrangement of the waterwall tubes with other implementations of combustion chamber waterwalls occurring in the flow boilers have been compared, thanks to which it was 
shown that the proposed implementation is more advantageous in terms of boiler operation parameters, which has a positive effect on fuel consumption as well as reduction of emission of pollution and greenhouse gases into the atmosphere.

One of the items presenting cross-sectional methods of analyzing the phenomenon of heat exchange taking place in the furnace of the fluidized bed boiler is [28]. In this publication, the author analyzes in detail the phenomenon of heat exchange in a simplified - twodimensional and three-dimensional fluidized bed model, discusses the methods of experimental monitoring of this phenomenon and discusses the results obtained by using a numerical model of fluidized bed simulation compared to the results of measurements of fluidized bed parameters using thermographic and infrared radiation.

\section{References}

1. V. A. Lokshin, D. F. Peterson, A. L. Schwarz, Standard methods of hydraulic design for power boilers (CRC Press, Berlin, Germany, 1988)

2. B. Węglowski, Identification of the thermal operating conditions of boilers combustion chamber walls (in polish) (Wydawnictwo Politechniki Krakowskiej, Cracow, Poland, 1995)

3. W. Zima, The inverse problem of heat conduction in pressure elements of boilers (in polish) (Wydawnictwo Politechniki Krakowskiej, Cracow, Poland, 1996)

4. S. Gradziel, Identification of transient thermal state of thick-walled boiler elements (in polish) (Wydawnictwo Politechniki Krakowskiej, Cracow, Poland, 1997)

5. W. Zima, Simulation of the transient processes in power boilers steam superheaters (in polish) (Wydawnictwo Politechniki Krakowskiej, Cracow, Poland, 2004)

6. S. Grądziel, Modeling of flow-thermal phenomena occurring in the boiler's evaporator with natural circulation (in polish) (Wydawnictwo Politechniki Krakowskiej, Cracow, Poland, 2012)

7. S. Łopata, S. Grądziel, Energy machines and devices (in polish) 365-382 (Wydawnictwo Politechniki Krakowskiej, Cracow, Poland, 2013)

8. S. Łopata, S. Grądziel, Energy machines and devices (in polish) 71-90 (Wydawnictwo Politechniki Krakowskiej, Cracow, Poland, 2013)

9. J.Taler, P.Duda, B.Węglowski, W.Zima, S.Grądziel, T.Sobota, D.Taler, Fuel 88, 305-311 (2009)

10. S. Grądziel, Archivum Combustionis 35, 75-88 (2015)

11. S. Grądziel, K. Majewski, Chemical and Process Engineering 37, 2, 199-213 (2016)

12. S. Grądziel, K. Majewski, Procedia Engineering 157, 44-49 (2016)

13. K. Majewski, S. Grądziel, Chemical and Process Engineering 37, 2, 251-260 (2016)
14. S. Grądziel, K. Majewski, Journal Heat Transfer Engineering 39, 13-14, 1243-1250 (2018)

15. P. Basu, Circulating Fluidized Bed Boilers (Springer, London, UK, 2015)

16. S. Wiśniewski, T. S. Wiśniewski, Heat exchange (in polish) (WNT, Warsaw, Poland, 2013)

17. J. Pan, G. Wu, D. Yang, Applied Thermal Engineering 32, 41-48 (2012)

18. J. Pan, G. Wu, D. Yang, Applied Thermal Engineering 82, 225-236 (2015)

19. L. Wang, D. Yang, Z. Shen, K. Mao, J. Long, Applied Thermal Engineering 95, 42-52 (2016)

20. S. J. Goidich, R. J. Docherty, K. P. Meizer,. Modern Power Systems 32, 4, 29-32 (2012)

21. A. Jasiński, Diagnostics of water boilers - main causes of failure of pressure elements (in polish) (Energopomiar, Gliwice, Poland, 2013)

22. W. Zima, M. Nowak-Ocłoń, Procedia Engineering 157, 200-206 (2016)

23. W. Zima, M. Nowak-Ocłoń, P. Ocłoń, Energy 92, 117-127 (2015)

24. W. Zima, M. Nowak-Ocłoń, P. Ocłoń, Energy 148 , 809-823 (2018)

25. P. Basu, P. K. Nag, Chemical Engineering Science 51, 1, 1-26 (1996)

26. W. Dobrzański, K. Jurek, W. Szwarc, Experimental research of the experimental OF-1,3 fluidized bed boiler (in polish) (Wydawnictwo Politechniki Warszawskiej, Warsaw, Poland, 1987)

27. S. J. Goidich, R. J. Docherty, K. P. Melzer, The World's First Supercritical FW-BENSON Vertical PC Boiler - The 750 MWe Longview Power Project (Foster Wheeler, 2011)

28. A. Patil, Heat transfer in gas-solid fluidized beds (Technische Universiteit Eindhoven, Eindhoven, Holland, 2015) 